\title{
Scrotal reconstruction with pedicled gracilis muscle flap following Fournier's gangrene: a case report and literature review
}

\author{
Oluwatosin Stephen Ilori ${ }^{1 *}$, David. A. Onilede ${ }^{2}$, Ademola. A. Popoola ${ }^{3}$, Olorunnisola O. Olatide ${ }^{1}$ and \\ Chidi O. Ugwuoke
}

\begin{abstract}
Background: Fournier's gangrene is an acute soft tissue necrotizing infection involving the perineum and the external genitalia which can result in a major loss of the scrotal wall with exposure of the testicles. Reconstruction of such major defect is quite challenging; the use of pedicled gracilis muscle flap helps to create an aesthetically acceptable scrotum with minimal donor site morbidity.

Case presentation: We described the case of a 60-year-old man with a large scrotal loss from Fournier's gangrene following bladder outlet obstruction and perineal abscess. He had multiple debridement and reconstruction with pedicled left gracilis muscle flap with a good aesthetic and functional post-operative outcome. The major challenge encountered was the loss of the skin graft as a result of the retraction of the muscle flap due to too early ambulation; this can thus be avoided by adequate pre-operative counseling and enforcing bed rest.
\end{abstract}

Conclusions: The use of gracilis muscle flap in the reconstruction of large scrotal defect described in this report has the additional advantage of creating a pliable and soft feel like that of the original scrotum with minimal donor site morbidity.

Keywords: Gracilis muscle flap, Fournier's gangrene, Scrotal reconstruction

\section{Background}

Fournier's gangrene is an acute soft tissue necrotizing infection involving the perineum and the external genitalia, commonly occurring in men. It can result in a major loss of scrotal wall with exposure of the testicles [1]. Serial debridement is often required to remove all necrotic tissues, control the rapid spread of the infection and ensure a wound bed suitable for coverage [2]. Reconstruction of the scrotal and perineal region following a large defect is quite challenging [3]. The main objectives of scrotal reconstruction thus include creating a scrotum which is cosmetically acceptable, sensate and durable and

\footnotetext{
${ }^{*}$ Correspondence: tosinilori2002@yahoo.com

1 Plastic and Reconstructive Surgery Unit, Department of Surgery, LAUTECH Teaching Hospital, PMB 4007, Ogbomoso, Oyo state, Nigeria Full list of author information is available at the end of the article
}

restoring the psychological and social confidence of the patient [1].

Different methods have been used in the past to achieve soft tissue cover following Fournier's gangrene; they are all, however, associated with their benefits and drawbacks. The burying of the testes in the thigh, though simpler has been associated with repeated trauma to the testes, testicular atrophy and unpleasant aesthetic appearance $[4,5]$. The undermining of the remnant perineal skin has also been used with good results but it is limited to defects less than half of the scrotum [6]. The use of skin graft alone has also been widely embraced but it cannot be used solely for major scrotal loss, and it is thin and adheres to the testes, thus easily showing its outline and less cosmetically acceptable. As a result of the drawbacks of the above modalities, the coverage of 
major scrotal defects with flaps either as fasciocutaneous, musculocutaneous or muscle flaps are preferred for a better appearance and psychological outcome [5]. The use of gracilis muscle flap in the reconstruction of large scrotal defect described in this report has the additional advantage of creating a pliable and soft feel like that of the original scrotum with minimal donor site morbidity. In addition, the gracilis muscle is easily conformed to the shape of the testes during reconstruction unlike the fasciocutaneous flap, and it also sags moderately under gravity like the original scrotum with time. The aim of this present study is to report a case of scrotal reconstruction with gracilis muscle flap, to highlight the challenge(s) that can be associated with this flap and the various measures that can help to ameliorate them.

\section{Case presentation}

A 60-year-old male presented at the emergency room with inability to pass urine, painful lower abdominal swelling and scrotal swelling 4 days prior presentation. There were obstructive and irritative urinary symptoms, high grade fever and discharge of pus from multiple points in the perineum. He also had a history of poorly treated urethritis in the past but there were no other co-morbidities. Examination findings at presentation showed a middle aged man who was conscious but in painful distress, not pale but dehydrated. The scrotum was grossly edematous, and most part of the scrotal skin was necrotic with foul smelling brownish exudate; copious purulent exudate was also noticed from the perineal region. Digital rectal examination revealed that the prostate was not enlarged, and the rectum was filled with well-formed stool. The full blood count done showed neutrophilic leukocytosis with toxic granulations. The abdominopelvic ultrasound scan showed a normal sized prostate with smooth outline. He was not diabetic, and the HIV I and II tests were negative. He was resuscitated and had urethral catheterization to relieve the obstruction. Debridement and drainage of pus was done, and it was followed by daily dressing with honey and sitz bath. The clinical findings prior to reconstruction showed loss of more than three fourth of the scrotal skin, and the exposed testicles and cords were covered with granulation tissue with some necrotic tissue at the distal part (Fig. 1); there was also a perineal defect measuring $12 \mathrm{X} 5 \mathrm{~cm}$.

Four weeks into admission, under spinal anaesthesia, he had further debridement and scrotal reconstruction with pedicled left gracilis muscle flap and split thickness skin graft while secondary closure was also done for the perineal wound at the same sitting. Following debridement, the testicles were syndactylised using a vicryl 0 suture, and the remnant scrotal skin was mobilized

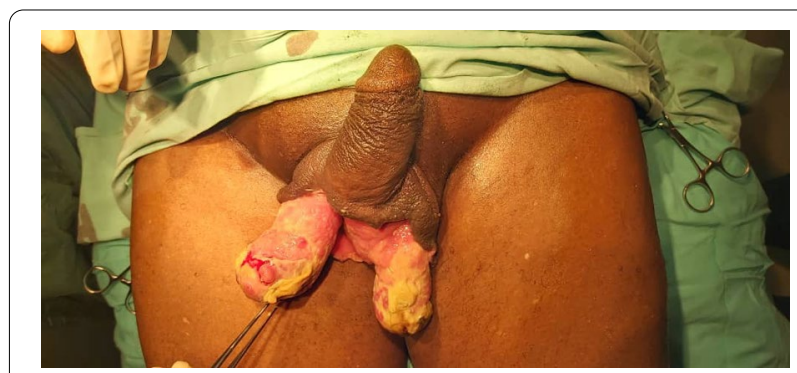

Fig. 1 The scrotal defect with exposed testicles at reconstruction

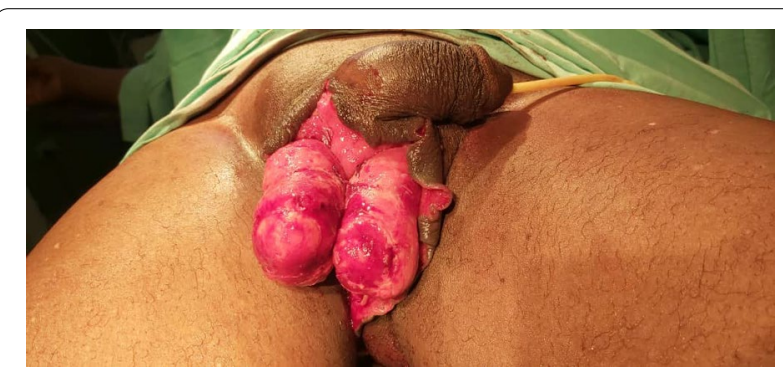

Fig. 2 The syndactilized testicles after debridement

(Fig. 2). A proximal-based gracilis muscle flap was raised from the left thigh using a skin incision placed 4-cm-posterior to an imaginary line drawn from the pubic tubercle to the medial femoral condyle with the hip abducted and externally rotated and the knee flexed (Fig. 3). The flap was taken through a subcutaneous tunnel and inset into the wound to cover the exposed testes (Figs. 4, 5). A fenestrated split thickness graft harvested from the anterior right thigh was then applied over the reconstructed scrotal sac. The donor site for the gracilis flap was closed directly in two layers with a drain left in situ (Fig. 6). Six days post-operative, the patient commenced ambulation contrary to instruction and had retraction of the gracilis muscle flap with $100 \%$ skin graft loss; he also had superficial dehiscence of part of the perineal wound (Fig. 7). The necrotic skin graft was debrided, and the patient was commenced on daily dressing with dilute honey. Eight days after, the residual scrotal defect was closed by advancing the muscle flap and closing the residual skin over it with a good post-operative outcome (Figs. 8, 9). The patient is currently being followed up at the plastic surgery and urology clinics.

\section{Discussion}

Different methods have been tried in the coverage of scrotal defects resulting from Fournier's gangrene. The most appropriate option used is usually based on the location and extent of the wound as well as the amount of 


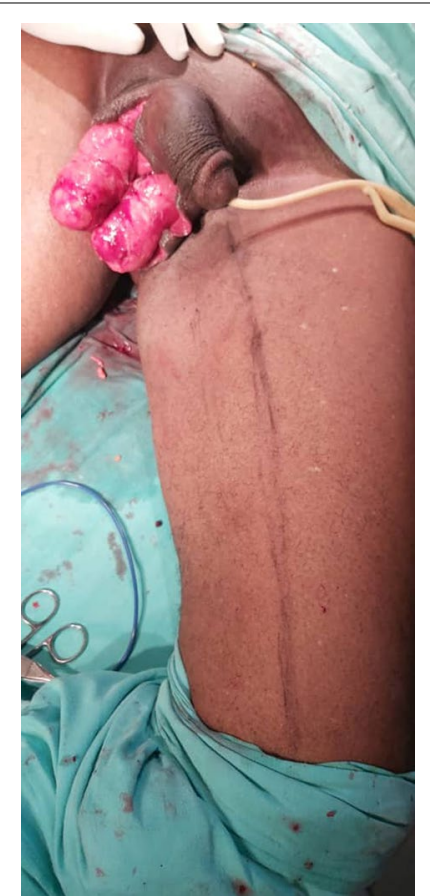

Fig. 3 The skin incision marking for the proposed gracilis muscle flap

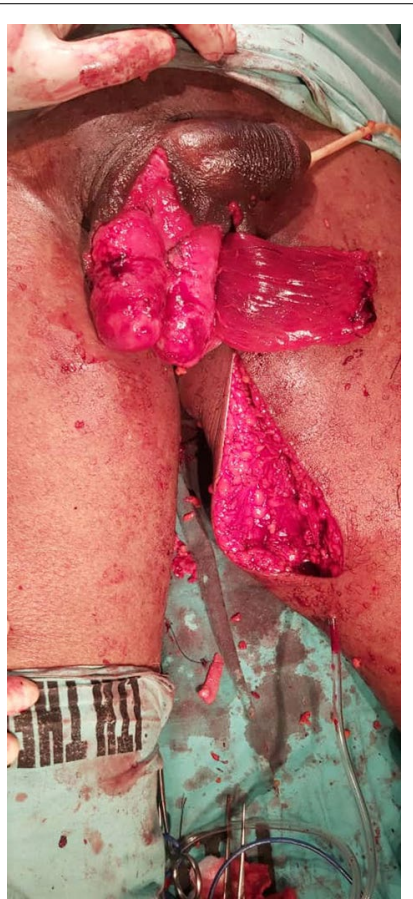

Fig. 4 The muscle flap before insetting

viable tissue present. Reconstructing the scrotum is often an herculean task because of the precarious blood supply to the scrotal wall and the adjoining tissue following the

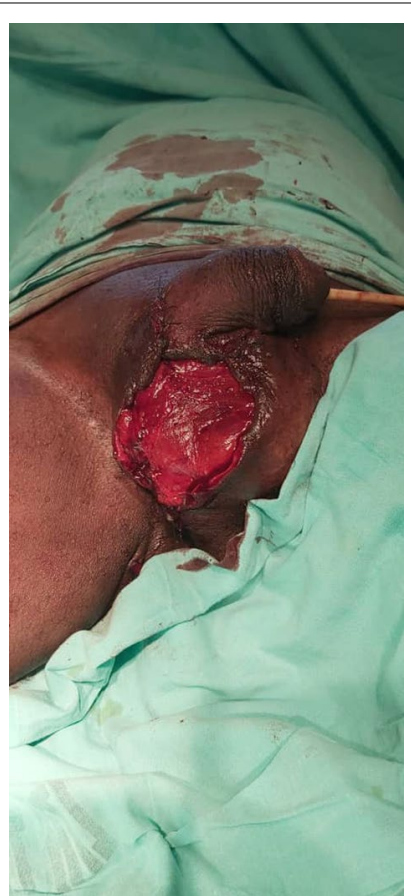

Fig. 5 The muscle flap already inset into the wound

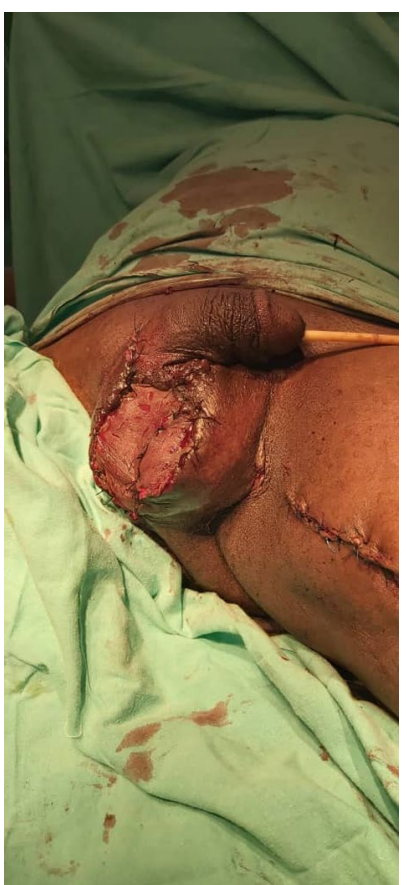

Fig. 6 The fenestrated graft placed on the inset muscle flap

gangrene [6]. The perineal bacterial flora, difficult immobilization of the repaired site, and the contour of the testes usually make scrotal coverage difficult [1]. Very large 


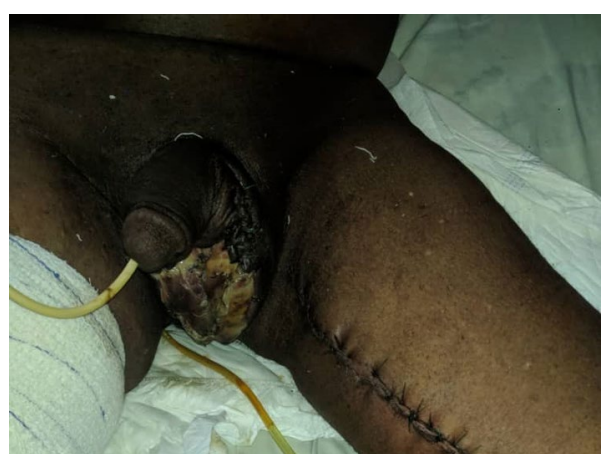

Fig. 7 The necrotic skin graft following the retraction of the muscle flap

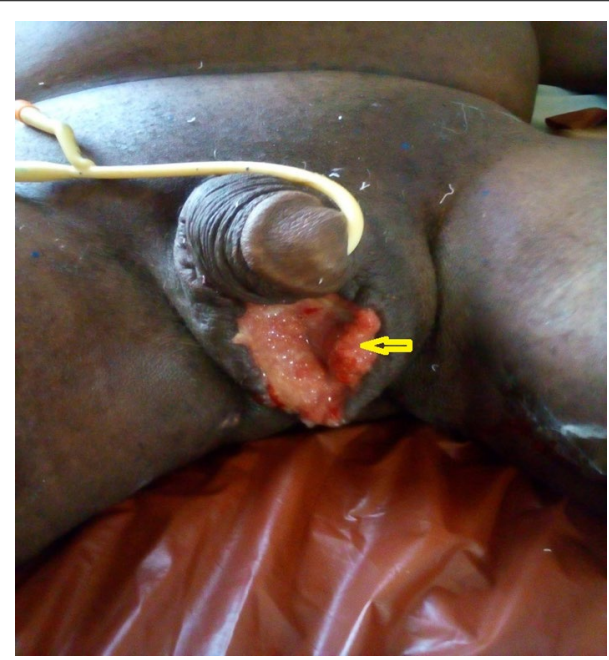

Fig. 8 The edge of the retracted muscle following debridement

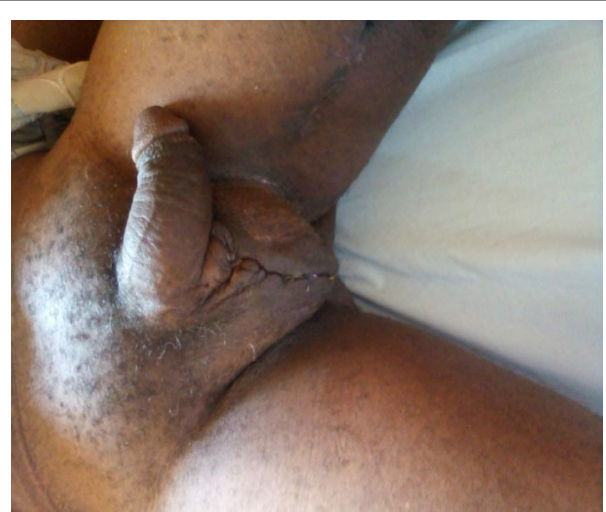

Fig. 9 The reconstructed scrotum at follow-up defects with deep cavities can be appropriately managed with the use of muscle or myocutaneous flaps like gracilis flap which was used in the index case [2,3]. The gracilis muscle flap is a type II flap that is based majorly on the ascending branch of the medial circumflex femoral artery $[2,7]$.

In the index patient, the pedicled gracilis muscle flap was chosen because it was close to the scrotal area, and it is ideal for coverage of large scrotal defects with deep cavities. It also serves as a good recipient site for skin grafts, thus removing the risk of skin paddle necrosis which is associated with the myocutaneous flap. [5] On the other hand, the limitations of the gracilis muscle flaps include loss of muscle function at the donor area and the presence of an additional scar on the thigh. In this case report, scarring at the donor site was limited and acceptable to the patient, and there was no functional deficit in gait. Following scrotal reconstruction, wound infection can be a major challenge, in this report however, there was no major wound infection. In the case reported by Katusabe et al., half of the skin graft got necrosed following infection, but the gracilis muscle flap was unaffected [1]. In our report, however there was $100 \%$ skin graft loss, and it was due to retraction of the muscle following early mobilization of the patient against instruction. As a result of this, enforcing bed rest following surgery is very vital to ensure a good flap outcome. Furthermore, the donor site of this flap can also be closed primarily with little or no morbidity. In view of the above advantages, the gracilis muscle flap is a very good choice for covering large scrotal defect, and it will give an acceptable outcome if the highlighted pitfalls are avoided.

\section{Conclusions}

In conclusion, the pedicled gracilis muscle flap can be reliably used to cover large scrotal wounds especially those with deep cavities. It gives a durable coverage which is resistant to infection. It is easily elevated and inset into the defect because it is close to the scrotal area.

\section{Abbreviation}

HIV: Human Immunodeficiency Virus.

\section{Acknowledgements}

We appreciate the patient for giving consent for this publication and also all clinical staff that were involved in the management of the patient.

\section{Authors' contributions}

IOS contributed to the conception, literature search, design of the work and final write-up DAA, PAA, OOO and UCO all contributed to the literature search, design of the work and final write-up. All authors have read and approved the manuscript.

\section{Funding}

No external funding was received for this study. 


\section{Availability of data and material}

Data sharing is not applicable to this article as no datasets were generated or analyzed during the current study.

\section{Declarations}

Ethics approval and consent to participate

The need for ethical approval was waived by LAUTECH Teaching Hospital Ethical Review Committee.

\section{Consent for publication}

Informed consent was obtained from the patient for publication of this case report and accompanying images.

\section{Competing interests}

The authors declare that they have no competing interest.

\section{Author details}

'Plastic and Reconstructive Surgery Unit, Department of Surgery, LAUTECH Teaching Hospital, PMB 4007, Ogbomoso, Oyo state, Nigeria. ${ }^{2}$ Burn and Plastic Surgery Unit, Department of Surgery, Federal Medical Centre, Keffi, Nasarawa State, Nigeria. ${ }^{3}$ Department of Surgery, University of Ilorin Teaching Hospital, Ilorin, Kwara State, Nigeria.

Received: 6 October 2021 Accepted: 16 November 2021

Published online: 24 December 2021

\section{References}

1. Katusabe LJ, Balumuka D, Hodges A (2013) Scrotal reconstruction with a pedicled gracilis muscle flap after debridement of Fournier's gangrene: a case report. East Afr Med J 90(11):375-378

2. Kim SW, Kim BJ, Seul CH (2006) Scrotal reconstruction using gracilis muscle flap in Fournier's gangrene. Plast Reconstr Surg 118(4):152-153

3. Chen SY, Fu JP, Chen TM, Chen SG (2011) Reconstruction of scrotal and perineal defects in Fournier's gangrene. J plast Reconstr aesthet surg 64:528-534

4. Islam MT, Dey PK, Kamal AHM, Uddin MF (2017) Evaluation of scrotal reconstruction with thigh flap. Bang Med J Khulna 50:13-17

5. Karki D, Patel PK, Narayan RP (2016) Penoscrotal defect: a functional, esthetic, and psychological challenge. Plast Aesthet Res 3:64-67

6. Karian LS, Chung SY, Lee ES (2015) Reconstruction of defects after Fournier's Gangrene: a systematic review. E Plasty 15:155-169

7. Kayikcioglu A (2003) A new technique in scrotal reconstruction: short gracilis flap. Urology 61:1254-1256

\section{Publisher's Note}

Springer Nature remains neutral with regard to jurisdictional claims in published maps and institutional affiliations.

\section{Submit your manuscript to a SpringerOpen ${ }^{\odot}$ journal and benefit from:}

- Convenient online submission

- Rigorous peer review

- Open access: articles freely available online

- High visibility within the field

- Retaining the copyright to your article 